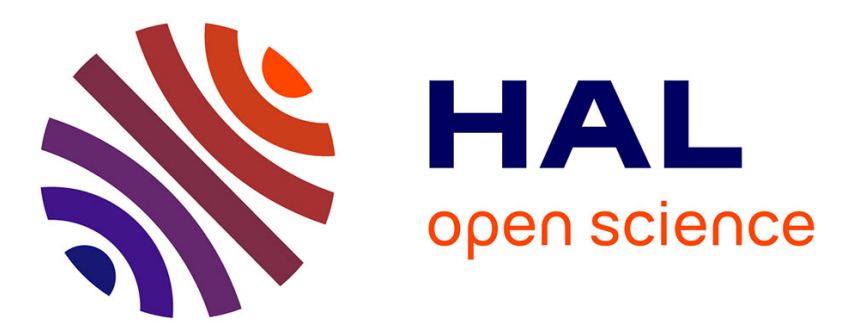

\title{
THE COMBINING OF DIELECTRIC AND ANELASTIC RELAXATION MEASUREMENTS IN THE STUDY OF POINT DEFECTS IN INSULATING CRYSTALS
}

A. Nowick

\section{To cite this version:}

A. Nowick. THE COMBINING OF DIELECTRIC AND ANELASTIC RELAXATION MEASUREMENTS IN THE STUDY OF POINT DEFECTS IN INSULATING CRYSTALS. Journal de Physique Colloques, 1985, 46 (C10), pp.C10-507-C10-511. 10.1051/jphyscol:198510112 . jpa-00225313

\section{HAL Id: jpa-00225313 https://hal.science/jpa-00225313}

Submitted on 1 Jan 1985

HAL is a multi-disciplinary open access archive for the deposit and dissemination of scientific research documents, whether they are published or not. The documents may come from teaching and research institutions in France or abroad, or from public or private research centers.
L'archive ouverte pluridisciplinaire HAL, est destinée au dépôt et à la diffusion de documents scientifiques de niveau recherche, publiés ou non, émanant des établissements d'enseignement et de recherche français ou étrangers, des laboratoires publics ou privés. 
Colloque ClO, supplément au $\mathrm{n}^{\circ} 12$, Tome 46, décembre 1985 page Cl0-507

\title{
THE COMBINING OF DIELECTRIC AND ANELASTIC RELAXATION MEASUREMENTS IN THE STUDY OF POINT DEFECTS IN INSULATING CRYSTALS
}

\author{
A.S. NOWICK \\ Henry Krumb School of Mines, Columbia University, New York, \\ NY 10027, U.S.A.
}

\begin{abstract}
Résumé - En ce quj concerne 1 'êtude dés défauts ponctuels dans les cristaux isolants, nous montrons qu'il est possible d'obtenir.plus d'informations sur la cinétique de ces defauts en utilisant simultanément des mesures de relaxation diélectriques et de relaxation anélastiques, qu'en utilisant ces dernieres uniquement. Cela est dû au fait que ces deux types de mesures concernent différents modes excités de relaxation. Plusieurs examples illustrant ce propos sont donnés, en particulier, nous avons étudié: de cristaux de quartz contenant des défauts AT-Na, des cristaux de Céria contenant des defauts YVo ( $V_{0}$ représentant une lacune d'oxygène ionisé) et de Céria contenant des ions $\mathrm{Sc}^{3+}$ qui sont isolés et vont dans une configuration non-centrée.
\end{abstract}

\begin{abstract}
In the study of point defects in insulating crystals, it is shown that more information about defect kinetics is obtainable by combining measurements of dielectric relaxation with those of anelastic relaxation than from anelasticity alone. This is true because the two types of experiments usually excite different relaxational modes. Examples of such studies are given, including: quartz crystals with Al-Na defects, ceria with $\mathrm{VV}_{0}$ defects (where $\mathrm{V}_{0}$ is an oxygen-ion vacancy), and ceria with isolated $\mathrm{Sc}^{3+}$ ions, which go into an off-center configuration.
\end{abstract}

\section{I - INTRODUCTION}

Anelastic relaxation due to point defects in crystals is usually describable in terms of one or more Debye peaks, of the form

$$
\tan \phi=\frac{\delta S}{S} \frac{\omega \tau}{1+\omega^{2} \tau^{2}}
$$

where $\phi$ is the angle of lag of strain behind the stress (the "loss angle"), $s$ is the appropriate compliance and $\delta s$ the magnitude of its relaxation, w the angutar frequency and $\tau$ the relaxation time. Because $\tau^{-1}$ generally obeys an Arrhenius relation, $\tan \phi$ yields a symmetric peak either as a function of $1 / T$ (where $T$ is absolute temperature) or of $\log \omega$. Such Debye peaks are observed whenever the symmetry of point defects is lower than that of the crystal in which they reside. In such a case the defect has $n$ equivalent orientations amoung which reorientation may occur. The detailed theory $/ 1,2 /$ shows that $n$ orientations give rise to $n$ relaxational modes, each of which has its own unique relaxation time, $\tau$. For each mode, $\tau^{-1}$ may be expressed in terms of all the possible reorientation frequencies. Detailed expressions have been worked out for every crystal and defect symmetry. /1/

Some relaxational modes are excited by various stress systems. Others may be excited by an electric field (in dielectric materials) giving rise to a dielectric loss of the form

$$
\tan \delta=(\delta \varepsilon / \varepsilon) \omega \tau /\left(1+\omega^{2} \tau^{2}\right)
$$


where $\delta$ is the dielectric loss angle, $\varepsilon$ the appropriate dielectric constant, and $\delta \varepsilon$ the relaxation of $\varepsilon$ which depends on the concentration of the defects and their electric dipole strength.

In the present paper, I shall confine myself entirely to the study of ionic materials (insulators) in which dielectric as well as anelastic relaxation can be measured. It is intended to show that greater information about defect migration processes may be obtained by combining these two types of measurements than from anelasticity alone.

Some of the possibilities to expected, in order of increasing complexity, are the following:

1) The relaxation rate, $\tau^{-1}$, for dielectric and anelastic relaxation are the same.

2) The two relaxation rates are controlled by the same atomic jump but involve different geometrical factors. (In this case, the activation energy is the same for both relaxations but the preexponentials differ by a factor that is characteristic of the defect involved).

3) The two relaxation rates may be controlled by different atomic jumps, so that their activation energies also differ.

These various possibilities will be illustrated herein by three examples taken from recent studies of interesting ionic crystals.

\section{THE CASE OF $\alpha$ - QUARTZ WITH A]-Na DEFECTS}

Crystalline quartz ( $\alpha$-quartz), whether naturally occurring or synthetically grown, generally contains $A ?^{3+}$ ions substituting for $\mathrm{Si}^{4+}, / 3 /$. Because of the charge difference, the $\mathrm{Al}^{3+}$ ion is compensated by an interstitial monovalent ion, e.g. $\mathrm{Na}^{+}$, $\mathrm{Li}^{+}$or $\mathrm{H}^{+}$. The $\mathrm{Al}^{3+}$ thus sits at the center of a distorted $\mathrm{AlO}$ tetrahedron with the monovalent interstial ion nearby. A model of the much-studied $\mathrm{Al}-\mathrm{Na}$ defect is shown in Fig. 1. The only symmetry of the tetrahedron is a single 2-fold $\left(C_{2}\right)$ axis, and since the $\mathrm{Na}^{+}$sits off of this axis, there are two equivalent positions for the $\mathrm{Na}^{+}$on the tetrahedron. The crystal, however is trigonal ( $D_{3}$ symmetry) with a 3 -fold axis along the $z$ direction (perpendicular to Fig. I), so that there are three differently oriented tetrahedra on which the defect may reside, each rotated by $120^{\circ}$ from the others. In this case, therefore, the defect is triclinic (no symmetry) and $n=6$. For such a defect it has been shown $/ 4 /$ that there are two types of relaxational modes. The type designated by letter $A_{2}$ (in group theoretical notation) is excited only by an electric field parallel to the 3 -fold screw axis ( $z$ axis). On the other hand, the type designated by letter $E$ is excited either by an electric field perpendicular to the $z$ axis, or by any stress system that contains shear components. The $E$ modes actualiy give rise to two relaxation times, but one of these requires migration of the $A l^{3+}$ ion, a process
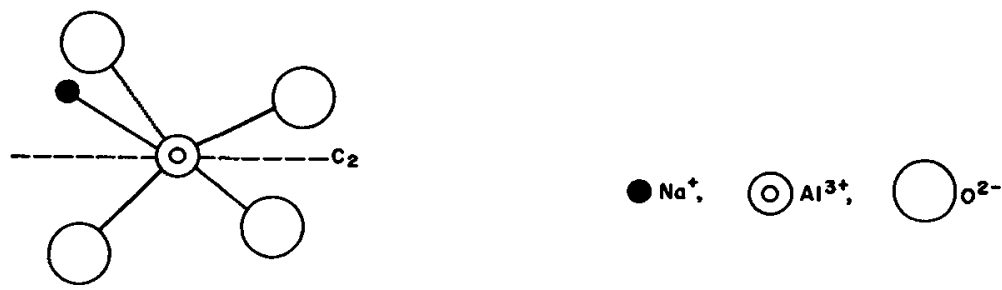

Fig. 1 - Model of distorted tetrahedron, the basic structural unit of $\alpha$-quartz, showing $\mathrm{Al}^{3+}$ replacing $\mathrm{Si}^{4+}$ with an associated interstitial $\mathrm{Na}^{+}$ion. The line $\mathrm{C}_{2}$ is the 2-fold symmetry axis. 
that can only occur at temperatures too high to be observable. The other relaxations are controlled by $\mathrm{W}_{\mathrm{Na}}$, the jump rate of the insterstitial $\mathrm{Na}$ ion across the $\mathrm{C}_{2}$ axis of the tetrahedron (see Fig. 1). The relaxation rates have been shown to be 141

$$
\tau^{-1}\left(A_{2}\right)=\tau^{-1}(E)=2 W_{N a}
$$

i.e., the same for both modes. Since the activation energy for this interstitial jump is very low, the relaxation peaks are observed at cryogenic temperatures (near $30 \mathrm{~K}$ for $1 \mathrm{kHz}$ ). Dielectric relaxation usually covers the frequency range of $1-.10$ $\mathrm{kHz}$ while the anelastic relaxation is observed in AT-cut acoustic reasonators vibrating at a fixed frequency of $5 \mathrm{MHz}$.

In view of Eq. (3) it is permissible to combine the data from both sources to obtain an Arrhenius plat which covers the entire range from $1 \mathrm{kHz}$ to $5 \mathrm{MHz}$. In this

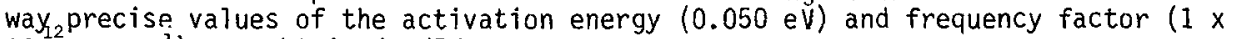
$10^{12} \mathrm{sec}^{-1}$ ) are obtained. /5/

It is noteworthy that both techniques can detect $\mathrm{Al}-\mathrm{Na}$ defects when they are present at a concentration as low as 1 ppm.

\section{III- CASE OF $\mathrm{CeO}_{2}$ WITH YVO DEFECTS}

Ceria $\left(\mathrm{CeO}_{2}\right)$ is a ceramic material that possesses the fluorite structure. When doped with ${ }^{2}$ lower valent cations (e.g.Ca ${ }^{24}$ or $\gamma^{3+}$ ), charge compensation occurs through the formation of oxygen-ion vacancies $\left(V_{0}\right)$. The material then becomes a good oxygen-ion conductor at high temperatures and is of interest for fuel cell applications. /6/ The trivalent dopants (e.g. $\mathrm{Y}^{3+}$ ) are of special interest. Here, for every two $Y^{3+} i$ on, we expect to obtain one $V_{0}$. At lower temperatures, these should associate to form a $Y_{2} V_{0}$ triplet. Since mobility on the cationic sublattice is frozen in at about $1000^{\circ} \mathrm{C}$, however, the formation of such triplets might not be kinetically possible at lower temperatures, where only the $V_{0}$ is mobile. Accordingly, we were led to expect that half of the $Y^{3+}$ ions were associated to form $Y V_{0}$ pairs (which carry a net positive charge), and the other half remain unassociated (carrying a net negative charge). Thus an array of charged defects is created. But how could we prove or disprove this hypothesis?

The structure of the $Y V_{0}$ defect is shown in Fig.2. This is a defect of trigonal symmetry in a cubic crystal, for which $n=8$. Such a defect should give rise to anelastic relaxation only under a shear stress of the type $\mathrm{S}_{44}$ (or uniaxial stress along $<111>$ and not under shear stress of type $s_{11}-s_{12}$ (or $<100>$ uniaxial stress):
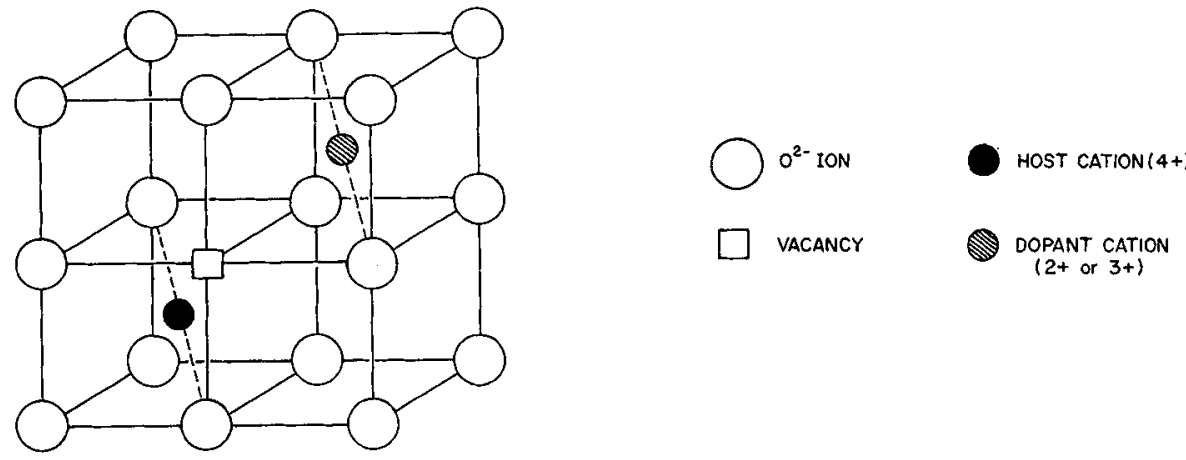

Fig. 2. Diagram of one-half the unit cell of a fluorite-type oxide showing a substitutional dopant cation paired with an oxygen-ion vacancy. 
Thus, the proposed model could be checked by anelastic studies if single crystals were available. Unfortunately, ceria is a ceramic of very high melting point, and single crystals are not available. Let us then consider utilizing dielectric relaxation. The modes excited dielectrically are those denoted by letter $\mathrm{T}_{1}$ while those excited anelastically are of type $T_{2}$. Since the nearest-neighbor jump $\mathrm{H}_{\mathrm{f}}$ vacancy provides access to al1 8 orientations of the $\mathrm{V}_{0}$ pair (see Fig.2), it is clear that all relaxation rates are controlled by the specific jump rate of the vacancy, which we call w. It has been shown $/ 2 /$ that

$$
\begin{aligned}
& \tau^{-1}\left(T_{2 g}\right)=4 w \\
& \tau^{-1}\left(T_{1 u}\right)=2 w
\end{aligned}
$$

In other words $\tau^{-1}$ (anelastic) $/ \tau^{-1}$ (dielectric) $=2$. This ratio is characteristic of this particular defect.

Experimentally, in an anelastic study reported in ICIFUAS $7 / 7 /$, we showed that for $\mathrm{Y}^{3+}$ concentrations below $\sim 1 \%$ a single Debye peak is obtained. (The broadening that develops at higher concentrations shows the onset of defect interactions and of higher clusters.) More recently, careful dielectric studies carried out at low $Y$ concentrations, showed that a ratio $\tau^{-1}$ (anelastic) $/ \tau^{-1}$ (dielectric) $=1.94$ was obtained. $18 /$ The closeness of this result to the theoretical ratio of 2 leaves little doubt as to the validity of the proposed model.

IV - IHE LOW - TEMPERATURE $\mathrm{Sc}^{3+}$ PEAK IN CERIA

Ceria may also be doped with $\mathrm{Sc}^{3+}$ which, like $\mathrm{Y}^{3+}$ is also trivalent but is a much smaller ion. From ionic conductivity data, it has been shown $/ 9 /$ that the ScV pair has a much higher binding energy than the $V V_{0}$ pair $(0.67 \mathrm{eV} v s .0 .2 \mathrm{eV})$. A study of the anelastic behavior of Sc - doped ceria shows a surprising result. In addition to the ScV pair peak, which is observed near $300 \mathrm{~K}$ (for a frequency of $8 \mathrm{kHz}$ ), an extra peak is observed at $125 \mathrm{~K}$, as shown in Fig. 3 . This extra peak does not occur for any of the larger trivalent cations, e.g., Y, Gd or La. Dielectric loss also shows a peak in the same low-temperature range. A study of double doped samples - i.e., doped with $Y$ as well as Sc - - provides convincing evidence that this new peak is not due to the $\mathrm{ScV}_{0}$ pairs, but to isolated $\mathrm{Sc}$ ioils. $/ 10 /$ However, the isolated substitutional Sc has cubic surroundings and could not give rise to relaxation, unless it goes off-center. The low activation energy is also consistent with motions involving less than one atomic distance. Our dielectric loss measure-

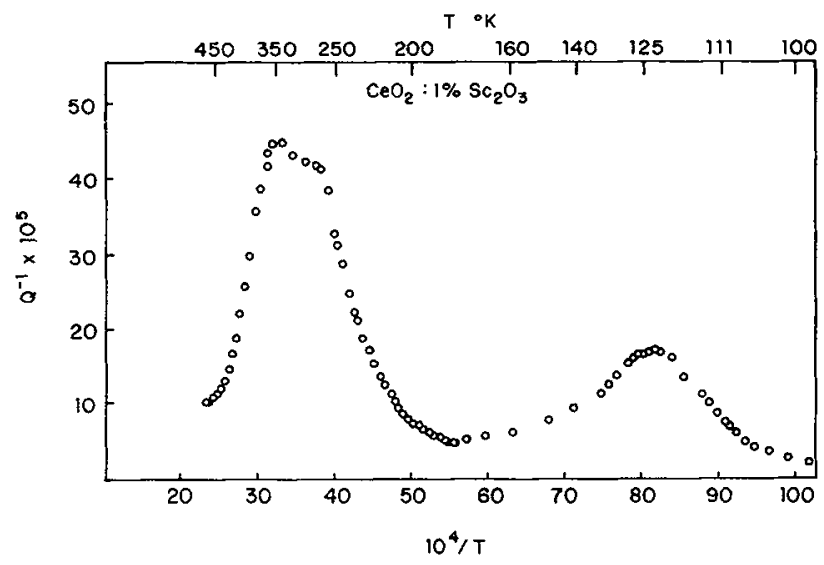

Fig. 3. Internal friction of ceria doped with 1 mole $\% \mathrm{Sc}_{2} \mathrm{O}_{3}$ as a function of reciprocal temperature. Frequency: $8 \mathrm{kHz}$. 
ments taken at several frequencies give an activation enthalpy of $0.22 \mathrm{eV}$. The location of the anelastic peak measured at only one frequency $(8 \mathrm{kHz})$, is not consistent with the dielectric Arrhenius plot, and, in fact, falls higher in $\tau^{-1}$ by a factor of 25. Such a large factor does not appear to be explicable as a difference in geometrical factors for the different relaxational modes. Rather, it suggests that the two modes are controlled by different atomic jumps. Such a result is consistent with a very low symmetry for the off-center configuration.

Interestingly enough, computer simulation calculations $/ 10 /$ support off-center behavior of this defect, not so much of the Sc ion itself, but rather of the cage of 8 surrounding oxygen ions. The calculation yields a defect configuration which has no symmetry (i.e. triclinic). See Figure 4.

CONCLUSIONS - It is hoped that these examples show that, in each case, the opportunity to study dielectric and anelastic relaxation together has given more useful information than if anelastic techniques alone were utilized.

ACKNOWLEDGMENTS - This work was sponsored both by the U.S. Department of Energy and the U.S. Air Force, RADC. The author also wishes to thank his present and former students: M.P. Anderson, R. Gerhardt, $W-K$ Lee, J. Toutouse and D-Y Wang, whose contributions are quoted herein.

\section{REFERENCES}

11/ Nowick, A.S., Adv. Phys. 16 (1967) 1.

12/ Nowick, A.S., in Point Defects in Solids, Vol.1, ed. Crawford, J.H. and Slifkin L.M., Plenum Press, N.Y. (1972), Chapter 3.

13/ Fraser, D.B., in Physical Acoustics, Vol.5, ed. Mason, W.P., Academic Press, N.Y. (1968), Chapter 2 .

/4/ Nowick, A.S. and Stanley, M.W., in Physics of the Solid State, ed. Balakrishna, S., Academic Press, N.Y. (1969), Chapter 11.

15/ Toulouse, J. and Nowick, A.S., J. Phys. Chem. Solids, in press.

16/ Steele, B.C.H., Solid State Ionics 12 (1984) 391.

17/ Anderson, M.P. and Nowick, A.S., J. de Physique io (1981), Colloque C5 - 823.

18/ Wang, D.Y. and Nowick, A.S., J. Phys. Chem. Solids 44 (1983) 639.

19/ Gerhardt-Anderson, R. and Nowick, A.S., Solid State Ionics 5 (1981) 547. $110 /$ Gerhardt-Anderson, R., Zamani-Noor, F., Nowick, A.S., Catlow, C.R.A. and Cormack, A.N., Solid State Ionics $9 / 10$ (1983) 931.

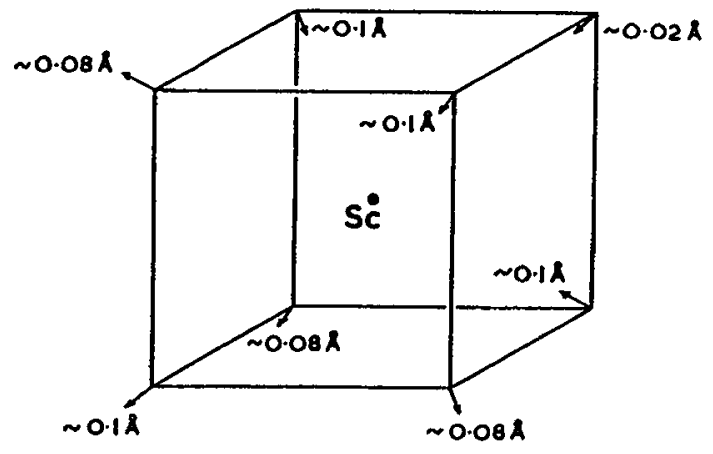

Fig.4. Displacements of $\mathrm{O}^{2-}$ ions about a substitutional $\mathrm{Sc}$ ion in $\mathrm{CeO}_{2}$, as determined by computer simulation. /10/ 